standards, if only because plagiarism is so easily detected and demonstrated. Plagiarists are either fools or desperate people. Concocting false data, cooking the books, is a more private matter and therefore harder to detect. Many heads of busy laboratories will be alarmed to think what may be happening without their knowledge - and will no doubt come to the conclusion that their only safeguard is to be directly involved in their own research, not merely as leaders but as colleagues of those who do the work. Even so, clearcut transgressions are likely to be rare. Less flagrant misdemeanours, or complaints thereof, are much more common. A helpful referee may find that his constructive comments become the gist of somebody else's publication. A member of a coordinated research programme may find that the contributions he has made to the planning of an enterprise turn up in the literature without his knowledge. Or references to important contributions to some field may be skimped for the sake of a false impression of originality. There is a lot of this about.

Remedies are unfortunately not easily devised. In the old days (half a century ago) it was the common practice for the head of a laboratory to take responsibility for everything that happened in it or was published from it. Grand old men used to terrorize their juniors yet give their work the stamp of authenticity. To turn back the clock would be impossible and would solve nothing, for even grand old men are capable of falsehood. Yet there is something in the view that the standards of behaviour would be improved if only laboratories as units engaged more freely and openly in discussions of their collective work. Falsehood is necessarily a private matter; open discussion must help to show it up - or even show that falsehood is unnecessary. It is only proper to record that many of the best laboratories are among the most willing to talk domestically. It would also help if external pressures on individual scientists could be abated. The competition for grants, promotion and kudos is the driving force. The need to publish derives from that. There is at least a chance that these pressures would abate substantially if the methods of financing research were only subtly changed. Shifting the balance of decision from external agencies to laboratories themselves would be certain to help. Is this the constructive course to follow after the disclosures of the past few weeks?

\title{
Pesticides in developing countries
}

Many years have passed since the argument about the future of the environment in which people live was sharply polarized, dividing those who considered that the surface of the Earth is a robust place and those who argued that, on the contrary, quite small changes affecting the ecological balance might have catastrophic consequences. Mercifully, these discussions are now conducted more moderately. Both sides in the old argument seem to have decided that everybody's interest will be served if consensus rather can conflict can be built around environmental problems. Unfortunately, however, it seems that old habits die hard. From time to time, vestiges of the sharp divisions of the 1960 s crop up in public statements and in the newspapers. One of the citadels of the extreme environmentalists appears to be the journal called New Internationalist, published by no less an organization than Oxfam, widely respected for the way in which it has tackled problems in developing countries with energy, compassion and imagination which are rare even for the most dedicated voluntary organizations.

New Internationalist is, however, over-imaginative in the way it tackles problems of the environment in developing countries. Thus, in the July 1980 issue of the journal, an article by the editorial staff of the journal which appears under the heading "Peddling pesticide" begins with the declaration that "until DDT was banned as a proven cancer-causing agent it was the penicillin of pesticides ...'. The article goes on to argue that the chemical companies, disconcerted to have been "caught pushing poisons", stopped manufacturing DDT in developed countries but set about selling their manufactured stocks in countries overseas. The objective of the article is to argue that the multinational chemical companies are using the developing world as an outlet for sales that would otherwise be frustrated and asks that Western governments should put a stop to their wicked ways. The argument thus brings together two important elements of the demonology of the extreme environmental movement of a decade ago - big business in general, and international business in particular, and pesticides in general, DDT in particular. Nobody quite understands where these demons have sprung from but no doubt they have their roots in a variety of improper practices in the past. For there is no doubt that at many periods in the past century developing countries have been exploited unfairly by business interests from overseas. Similarly, it is beyond dispute that DDT and the other organochlorine pesticides were used indiscriminately and perhaps irresponsibly soon after their introduction - although it appears that most of the damage that followed was in North America, where agriculture is intensive, and not in the developing countries. None of this, however, excuses what New Internationalist has to say about DDT, especially because what the developing countries need to know most urgently is more complicated.

The truth is that DDT is not a poison in any reasonable meaning of that word. Its acute toxicity to people is low, which is why it was widely used, a quarter of a century ago, for the control of mosquito populations in the areas of the world where malaria is endemic. Similarly, the evidence that DDT is "cancer-causing" is ambiguous in the ordinary meaning of those words. It is true that high doses of DDT fed to laboratory animals will induce cancer, as indeed they provoke disturbances of liver function. But there is no evidence that the use of DDT has in the past caused damage to people when used with suitable precautions and in circumstances that are appropriate. The more toxic organochlorine pesticides are more damaging to animal life, but even they have not been taken off the market in most industrialized countries because of the damage they might do to people - rather they have been controlled and sometimes banned for fear of what they might do to wildlife populations.

In developing countries, circumstances are different. It may be regrettable but it is true that many governments in developing countries are less squeamish about wildlife populations than are the governments (and the electorates) of industrialized countries. New Internationalist would be fighting a good cause if it sought to alert them to the importance of a balanced wildlife population and to the importance of refraining from needlessly disturbing the natural ecology. In due course, many such governments would no doubt follow industrialized states in controlling DDT for fear of unwanted effects on the wildlife population. But for many of these governments there is a more urgent reason why powerful pesticides such as DDT should be used with discrimination. The original enthusiasm for the use of DDT in controlling malaria has evaporated now that problems of insecticide resistance have become natural restraints on what can be accomplished. Similarly, in the industrialized countries which practise intensive agriculture, the United States and Western Europe in particular, there are growing dangers that the uncontrolled use of pesticides may serve chiefly to stimulate the emergence of resistant insects. The difficulty is that such problems cannot be solved simply by taking one, or even several, offending chemicals off the market - somehow, instead, their use has to be planned imaginatively. Is not this the point that New Internationalist and its parent organization should be seeking to establish? 